\title{
Asymmetrical Flow Field-Flow Fractionation Coupled to ICP-MS for Characterization of Trace Metal Species in the Environment from Macromolecular to Nano-Assemblage Forms: Current Challenges for Quantification
}

\author{
Isabelle A. M. Worms* and Vera I. Slaveykova
}

\begin{abstract}
Asymmetrical flow field-flow fractionation (AF4) is a powerful technique employed for the separation of macromolecules, nanoparticles, and their assemblages according to their hydrodynamic behavior. It is well known that at this size range, complex interactions can occur between components (e.g. surface adsorption, aggregation) controlling the fate of trace metals (TMs) bound to them. AF4 coupling to inductively coupled plasma mass spectrometry (ICP-MS) allows the quantification of metal-containing species at trace levels present in environmental and biological systems on a size-composition basis. The combination of AF4-ICP-MS with other online detectors provides additional information that allows the assessment of the origin of analytes present in mixtures and complex matrixes with minimal sample preparation, which is crucial for understanding the behavior of trace metal contaminants. Despite the increasing use of AF4-ICP-MS in environmental contexts, we acknowledge that the quantification of inorganic species using such combined techniques requires further development of standardized procedures and need certified reference materials. In this review, we also discuss critical endpoints within the ICP-MS instrument coupled to AF4 that need to be controlled before quantitative measurements can be validated. Then, we illustrate how the combination of different online detectors in addition to ICP-MS offers an integrated picture of natural components states, thus providing key information on the changes in behavior of trace metal species and metallic nanoparticles (MNPs) as observed in both environmental samples and biofluids.
\end{abstract}

Keywords: Asymmetrical flow field-flow fractionation - Eco-corona and bio-corona - Environmental colloids . Nanoparticles $\cdot$ ICP-MS $\cdot$ Slot-flow technology

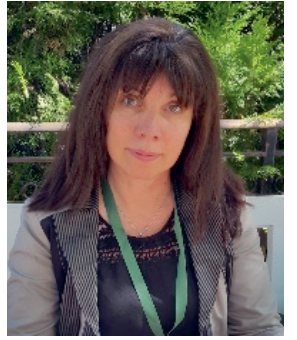

Dr. Vera I. Slaveykova is a full professor of environmental biogeochemistry and ecotoxicology at University of Geneva and president of the School of Earth and Environment Sciences. She works on the development of concepts and tools for a better understanding of the fundamental processes governing the behavior of trace elements and nanoparticles, and their interactions with various biotic and abiotic constituents of aquatic systems. Her current research interests and portfolio include (i) speciation and bioavailability of trace elements and nanoparticles in the aquatic environment; (ii) aquatic toxicology of inorganic contaminants and nanoparticles; transcriptomics and metabolomics; (iii) community ecotoxicology and biodiversity in aquatic systems.

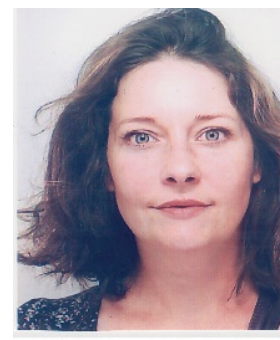

Dr. Isabelle A. M. Worms is a senior scientist of environmental biogeochemistry and ecotoxicology at the University of Geneva. She is a biochemist with a Master's Degree in molecular chemistry. Since her $\mathrm{PhD}$, her research interests include (i) gaining a better understanding of the bioavailability of trace metals; (ii) the development of AF4-ICPMS to assess the role of natural organic matter on the binding and dispersion of trace metals in surface water; and (iii) identifying key processes (environmental-corona formation, dissolution/formation, and aggregation) involved in nanoparticle stability using quantitative approaches.

\section{Introduction}

Determining the physicochemical speciation of trace metals (TMs) is a central topic in inorganic biogeochemistry, as various chemical and physical forms exhibit different fate, bioavailability, and impact on aquatic environments. Indeed, TMs exist in different 
chemical forms such as 'free' metal ions, metal bound to small inorganic and organic ligands, bound to or included into small metal-containing clusters (SMC), amorphous precipitates, nanosized particles (MNP), or soft-colloids (e.g. humic substances, HS), and finally bound to extracellular polymeric substances (EPS; e.g. polysaccharides, proteins, DNA, etc.) released from microorganisms. ${ }^{[1]}$ The reactivity of different TM forms, their transformations via complexation, adsorption, dissolution, aggregation, their biological availability and thus their ultimate impact in the environment are dependent on their physicochemical speciation. ${ }^{[2]}$

The chemical speciation of 'dissolved' TM species has received substantial attention in past decades, thanks to the development of chromatographic techniques coupled to ICP-MS, combined with ESIMS/MS. ${ }^{[3]}$ In contrast, the physical speciation and the implication of (nano-) particulate forms with regards to their reactivity is largely unexplored, ${ }^{[1 b, 2 b, 4]}$ due most likely to the lack of suitable techniques to characterize them. Rather limited in terms of size resolution, ultrafiltration (UF) or dialysis techniques, combined off-line with ICP-MS to measure the concentrations of TMs, are most often used to assess the proportion of colloidal metal forms and provide discrete molecular masses (MM) or size distributions in natural waters. ${ }^{[5]}$ However, losses of colloidal components and metal species by adsorption on the membranes have been reported.[6]

Several other analytical methods based on different principles also exist to characterize the natural and engineered MNPs. ${ }^{[1 a, 7]}$ For example, imaging techniques for the structural characterization of inorganic colloids, including light microscopy, electron microscopy, X-ray diffraction analysis, EXAFS, etc., are welldeveloped.[5e] Despite providing important structural information for evaluating the reactivity of inorganic-colloids, the lack of sensitivity makes them often inappropriate for the study of low concentrations of TMs bound to supramolecular, carbon-based, or colloidal carriers in natural aquatic environments. ${ }^{[8]}$ The detection at low environmental concentrations of MNPs can be achieved using a single-particle ICP-MS (sp-ICP-MS) that can provide useful information on NPs aggregation, large colloids aggregation, and hetero-aggregate composition. ${ }^{[9]}$ The detection limit in size with most commercially available ICP quadrupoles or time-of-flight mass detectors is usually limited for the elemental characterization of small MNPs (with diameter below $10 \mathrm{~nm}$ ). ${ }_{\text {[10] }}$ But recent developments on sector-field mass detectors, and use of optimized sample introduction procedures has led to an improvement in size detection limit.[11] sp-ICP-MS does not allow, however, a direct measurement of TM complexation by macromolecular species such as HS or TMs adsorption on mineral colloids, which are expected to be the most reactive species in environmental systems. ${ }^{[12 a, b]}$

Improved detection limits of size or MM and higher size resolution for macromolecular components can be achieved by online coupling of different separation techniques with ICPMS. The most commonly developed technique for this purpose is size exclusion chromatography (SEC), which allows the separation of HS, EPS, MNPs from their aggregates according to their mobility in a porous gel column. ${ }^{[13]}$ The metal content of small soft-colloidal species, such as HS can be measured by online ICP-MS.[14] Additionally, small MNPs can be separated from HS, according to their size. ${ }^{[15]}$ But such analysis is often limited by their low concentrations in the environment and often carried out using eluents with high ionic strength or surfactants to decrease unspecific interactions with the solid phase of the column, which can cause analytes' losses during the separation. It has been shown that the shear forces in the separation column can also break macromolecular structures or assemblages leading to truncate size distributions for larger analytes.

Asymmetrical flow field-flow fractionation (AF4) separates the analytes according to their diffusivity in a thin open channel.
Combined on-line with different detectors, it is used for a comprehensive characterization of nanoparticles and biopolymers, from proteins to large polysaccharides in their native or aggregated forms, as previously reviewed[16] and is a well-established technique for the characterization of natural organic and inorganic colloids. ${ }^{[7 b, 17]}$ Fig. 1 describes the different steps, principles and limitations occurring during sample fractionation by AF4 and how the information obtained by the different detectors allows the characterization of macromolecules and MNPs found in natural systems.

AF4 provides some advantages as compared to other size separation techniques, for the online ICP-MS analysis of low concentrations of analytes: $(i)$ minimal exposure of the analytes to surfaces that lessens their loss, (ii) possibility to separate analytes in mobile phases appropriate for ICP-MS, ${ }^{[20]}$ (iii) minimizing sample handling thus decreasing the risk of metal contaminations of the samples, and finally, (iv) allows the introduction of large volumes in the channel (up to $100 \mathrm{~mL}$ ) given the initial focusing step during sample injection, ${ }^{[21]}$ improving the detection limit of trace components. ${ }^{[22]}$

The present paper focuses on the determination of metal species in the size range between $300 \mathrm{Da}$ and $450 \mathrm{~nm}$ encountered in environmental and biological systems. We first provide an overview of the current main challenges for the quantitative use of AF4-ICP-MS for the size-based characterization of TM components in aqueous systems and discuss the existing solutions. The challenges related to AF4 separation/resolution and the potential loss of analytes were investigated by other authors.[18a,19,23] Thus, we will focus more specifically on the potential key parameters that must be controlled to ensure the correct quantification by the ICP-MS of the fractionated metalspecies. Then, we will provide different illustrations of the multidimensional information obtained with the use of series of online detectors that allows simultaneous quantification of these species according to their size and their nature. Such information is central for understanding their physicochemical speciation and thus their reactivity and impacts in aquatic environments and biofluids.

\section{Challenges and Solutions for Inorganic Species Quantification from ICP-MS Fractograms}

Metal fractograms are obtained via time-resolved data acquisition. Thus, when metal species elute from the AF4 channel, transient time-dependent signals forming peaks are recorded. Although well-established, AF4-ICP-MS suffers from a lack of rationalization for the handling of the connection between the separation channel and the ICP-MS, which often operates in a 'home-made' way. ${ }^{[24]}$ Different types of ICP-MS instrument can be used as online detectors, each having its own characteristics in terms of sample introduction and $\mathrm{m} / \mathrm{z}$ selectivity to avoid interferences for elemental detection. Ultimately, the measured ion signals are assumed to represent the respective metal concentration in the eluent and a suitable calibration strategy needs to be employed. Additionally, low concentration of natural nano-sized species can make their detection a challenge.

\subsection{Internal Standard and Interferences for $\mathrm{m} / \mathrm{z}$ Detection}

The use of an internal standard (ISTD) with an online introduction to monitor the drifts of ICP-MS sensitivity during analysis is often a warranted control for quantitative analysis of the total concentration of metals. Considering that the pressure during AF4 fractionation could change because of different fluxes engaged from focusing-elutionreleasing steps, the stability of the ICP-MS signals can potentially be affected during the analysis. Numerous examples where online mixing of the outflow with internal standards stabilized in nitric acid (often $\mathrm{Re}$ and/or $\mathrm{Rh}$ in $2-5 \% \mathrm{HNO}_{3}$ ) are available in the literature. 


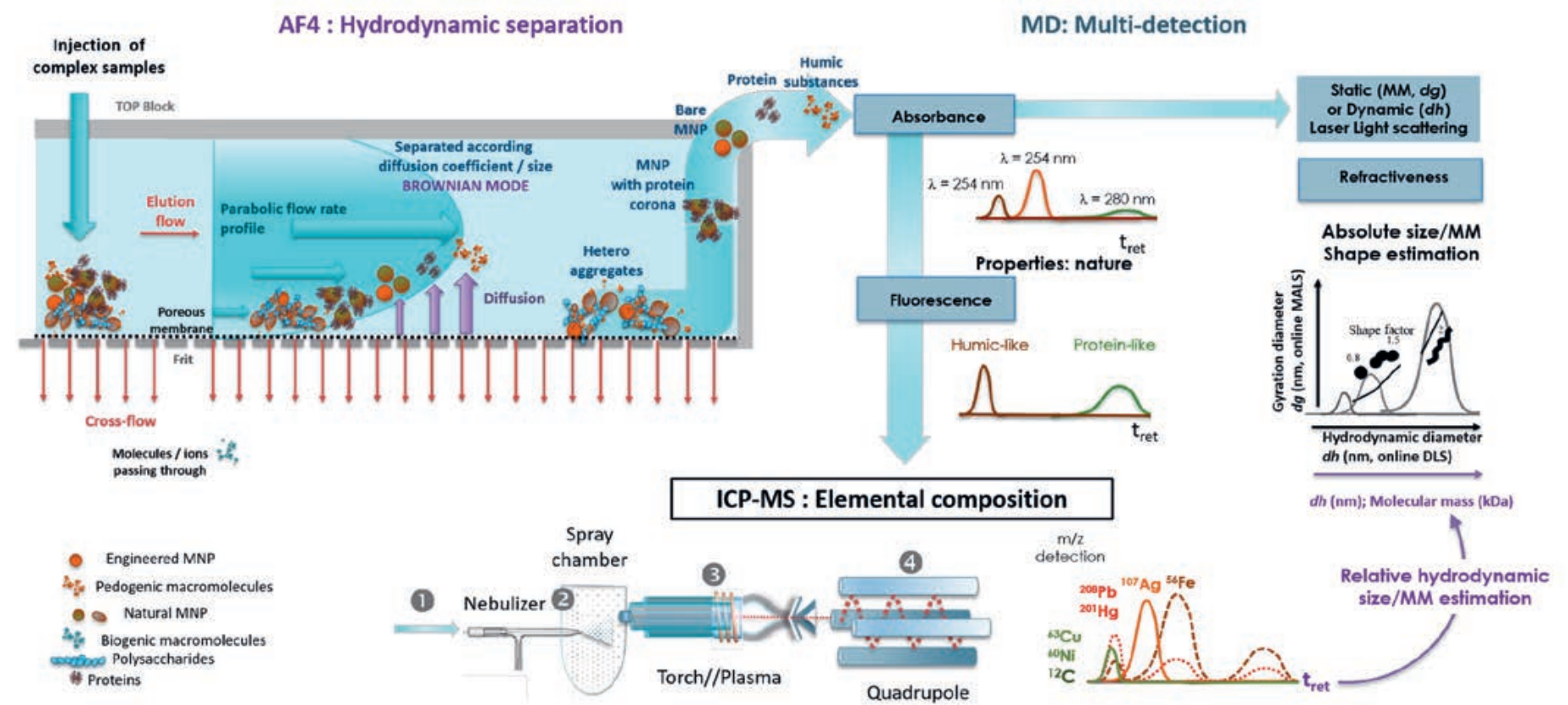

Fig. 1. Schematic representation of the separation (fractionation) of colloidal components $(<450 \mathrm{~nm})$ eluted according to a Brownian mode (diffusion-based) in the AF4 channel and followed by multi-detector responses within time (fractograms) allowing their characterization based on optical properties (absorbance, fluorescence), elemental composition (ICP-MS) or light scattering properties (dynamic or static light scattering (DLS and MALS)). During the injection in the AF4 channel, molecules and ions smaller than the ultra-filtration (porous) membrane size cut-off (minimum available, $\mathrm{MM}<300 \mathrm{Da}$ ) are passing through. Macromolecules and colloids (analytes) are retained on this membrane that forms an accumulation wall for the analytes of interest. The components are concentrated at the top of the channel by the action of an inverted flux (focus-flow). The separation of the analytes is then performed with a brownian elution mode in the AF4 channel owing to the higher mobility of smaller analytes, against the cross-flow applied (diffusion, purple arrows). According to the parabolic rate profile (blue arrows) generated by the combination of the elution and the cross-flow (red arrows), small-size analytes are eluted faster than large-size analytes. Their relative hydrodynamic size (diameters, $d_{h}$ ) or molecular mass $(\mathrm{MM})$ can be obtained by external calibration measuring the retention time $\left(t_{\text {ret }}\right)$ of individual standards with known $d_{h}$ or MM, or their diffusion coefficients evaluated using the AF4 elution theory. During the injection step, several artifacts can arise, such as inchannel aggregation or adsorption due to the increased concentration of analytes and interactions with the membrane. The recovery of each analyte depends on several factors (e.g. eluent ionic strength, presence of counter-ions, mass loading, cross-flow strength, and so on). Both the assessment of analyte loss and the size determination by AF4 can be difficult due to the diversity of natural components reactivities and eluents suitable for their elution, as compared to the behaviors of available standards. These points have been reviewed and discussed by several authors in the past. ${ }^{[18]}$ The use of absorbance detectors (UVvisD) or refractive index detectors (RID) is often employed for evaluation of analyte quantities. The fluorescence detectors (FluoD) are highly selective for detecting and deciphering the nature of organic components. The ICP-MS is by far the most selective, sensitive, and quantitative method for detection of species containing metal(-loids). The direct measurements by online dynamic light scattering (DLS) of hydrodynamic diameter $\left(d_{h}\right)$, or by static multi-angle light scattering (MALS) of MM or gyration diameter $\left(d_{g}\right)$ can be provided if the analytes are sufficiently concentrated and/or large. Provided that the $d_{g}$ is obtained by MALS, then shape factors can be derived based on their hydrodynamic behavior. Discussion concerning the relative sensitivity/selectivity of each of the detectors can be found in refs [7a,19]. In the particular case of ICP-MS, the detection is performed following several steps: Osample introduction, 2nebulization/transport, 3 plasma atomization/ionization, 4 quadrupole mass/charge $(\mathrm{m} / \mathrm{z})$ separation. Each step could be affected and thus lead to uncertainty in the measurements obtained by AF4-ICP-MS and will therefore be discussed in this review.

The choice of appropriate carrier liquid for ISTD is very important to avoid aggregation, salt deposits, nebulizer clogging, or modified atomization efficiency because of online acidification of the eluent and the analytes before introduction in the nebulizer.[25] In some cases, the carrier-sample mixture can generate toxic by-products that needs special waste management to protect users (e.g. use of $\mathrm{NaN}_{3}$ as bactericide in the eluent).

It is also known that spectral interferences for $m / z$ detection using common quadrupoles occur and need to be considered for accurate quantification. Less understood are the non-spectral interferences, such as the influence of eluent components (e.g. $\mathrm{Na}^{+}$or carbon introduction) on the ionization within the plasma or on the transport efficiency of the sample solution, that can lead either to the enhancement or suppression of the ICP-MS signal. These phenomena are element dependent and the use of internal standards is not always efficient to correct such deviation. ${ }^{[25,26]}$

The role of non-spectral interferences on element detection with AF4-ICP-MS was only taken into consideration in a few studies. For example, the sensitivity of Ag detection was enhanced when glutathione, but not other thiol-ligands, is used as a stabilizer for Ag-NPs in $10^{-4} \mathrm{M} \mathrm{NaOH}$ eluent; ${ }^{[27]}$ the presence of HS or use of ammonium carbonate as eluent was suspected to enhance the signal of As bound to humic substances in natural water samples, due to the presence of carbon; ${ }^{[28]}$ isopropanol was constantly supplied online before ICP-MS introduction to minimize changes in sensitivity caused by the protein corona enrobing Ag-NPs. [29] This 'carbon enhancement' effect was also used to improve the detection of some elements, such as Pt for Pt-NP measurement by adding $\mathrm{MeOH} 2 \%$ to the $1 \mathrm{mM}$ phosphate buffer $\mathrm{pH}=7$, SDS $0.01 \%$, eluent; ${ }^{[30]}$ or the detection of colloidal bound As and Se, by adding $\mathrm{MeOH} 3 \%$ to $10 \mathrm{mM} \mathrm{NaCl}$. ${ }^{[31]}$

Traditional isobaric interferences - also referred to spectral interferences ${ }^{[32]}$ - occur either due to similar isotopic mass for two different elements $\left(\right.$ e.g. ${ }^{204} \mathrm{Hg}^{+}$and $\left.{ }^{204} \mathrm{~Pb}^{+}\right)$or the same $\mathrm{m} / z$ of doubly charged ions (e.g. ${ }^{150} \mathrm{Nd}^{++}$and $\left.{ }^{75} \mathrm{As}^{+}\right)$and combination of elements forming polyatomic ions $\left(\right.$ e.g. ${ }^{40} \mathrm{Ar}^{16} \mathrm{O}^{+}$and $\left.{ }^{56} \mathrm{Fe}^{+}\right)$. Several approaches can be implemented to discriminate the element from its interference depending on the type of applications, as recently reviewed. ${ }^{[33]}$ This includes, for example, the reduction of oxides and doubly charged ions, the use of multi-isotopes detection, the technical improvement of commercial MS by introducing collision/reaction cells before quadrupole mass-selection, or in between two quadrupoles (QQQ- 
ICP-MS), ${ }^{[34]}$ or by increasing their mass-resolution (e.g. sector-field, recent $\mathrm{ToF}^{[35]}$ ) to increase the selectivity for the elements of interest.

In recent applications, AF4 was linked to simple quadrupole instruments, thus using a low mass-resolution, but complemented by reaction cells operating in kinetic energy discrimination mode $(\mathrm{KED})^{[36]}$ to remove polyatomic interferences. ${ }^{[37]} \mathrm{AF} 4$ can also be linked to high-resolution sector-field ICP-MS, and, depending on the element of interest and potential interferences, be either used at low mass resolving power $(\mathrm{R}=\mathrm{m} / \Delta \mathrm{m}>300)$ or higher mass resolution ( $\mathrm{R}>4000)$, the latter allowing for a wide range of spectral overlaps to be resolved from the analyte signal.[22,38]

Non-spectral interferences will not affect the determination of the hydrodynamic size of nano-sized species by AF4-ICP-MS, contrarily to those determined by ICP-MS in single particle mode. [26,39] But a spectral interference, formed from a species eluting at another time, can affect the size-speciation of a particular element. Both have implications for the quantification of nano-sized metalspecies, and the choice of proper internal standards ${ }^{[40]}$ and/or instrumental strategies for elements' detection must be considered.

\subsection{Unavailability of Certified Reference Materials and Calibration with Ionic Species}

The connections of the AF4 with the ICP-MS are also highly diverse, performed either directly to the nebulizer or by connection to a peristaltic pump, with or without a splitoff of the AF4 outflow. Calibration strategies employed for the quantification of metal-species involve continuous introduction of the standards into the ICP-MS and steady state measurements, or flow injection of standards measured in time-resolved way. ${ }^{[41]}$ Additionally, due to the lack of colloidal or macromolecular certified reference standards for all the inorganic species present in natural environments, ICP-MS calibration is often performed using their ionic counterparts obtained either by dilution of certified ionic single- or multi-element standard solutions. ${ }^{[42]}$

Trace cations are however often unstable in the eluents used commonly for AF4 fractionation (e.g. sodium chloride, ammonium carbonate, ammonium nitrate or biological buffers at neutral or slightly basic $\mathrm{pH}$ ). In most recent AF4 applications, calibrations were performed using constantly aspired ionic standards diluted in $\mathrm{HNO}_{3}(+/-\mathrm{HCl}$, depending on the element) as matrix and with continuous signal acquisition. Alternatively, standards can be introduced using an injection valve in the flow provided by AF4 to perform flow injection analysis (FIA) and recording transient signals with the ICP-MS. In addition to the difference in sample flow rates, changes in the matrix could affect the detection of elements by ICP-MS (see section 2.1), and lead to increased bias in the quantification of metal concentrations.

We tested three independent ways of quantifying the metal content for the peptide metallothionein (MT1) from fractograms obtained with the AF4 outflow coupled directly to the nebulizer (Fig. 2): using continuous introduction of ionic multi-element standards and non-transient time acquisition of the signals (external calibration) with dilution made in either (i) $2 \% \mathrm{HNO}_{3}$, or in (ii) $10 \mathrm{mM}$ HEPES pH = 7.0 (2-[4-(2-hydroxyethyl) piperazin-1-yl]ethanesulfonic acid, organic eluent for MT1 optimized fractionation) but supplemented with a chelator (2,2',2",2"'-(ethane-1,2-diyldinitrilo) tetra-acetic acid, EDTA) to stabilize cations in solution, and (iii) FIA of EDTA-stabilized standards where the outflow of the AF4 was coupled directly to the nebulizer ICP-MS. The quantification results obtained for ${ }^{66} \mathrm{Zn}$ and ${ }^{111} \mathrm{Cd}$ were independent of the calibration methodology chosen (Table in Fig. 2).

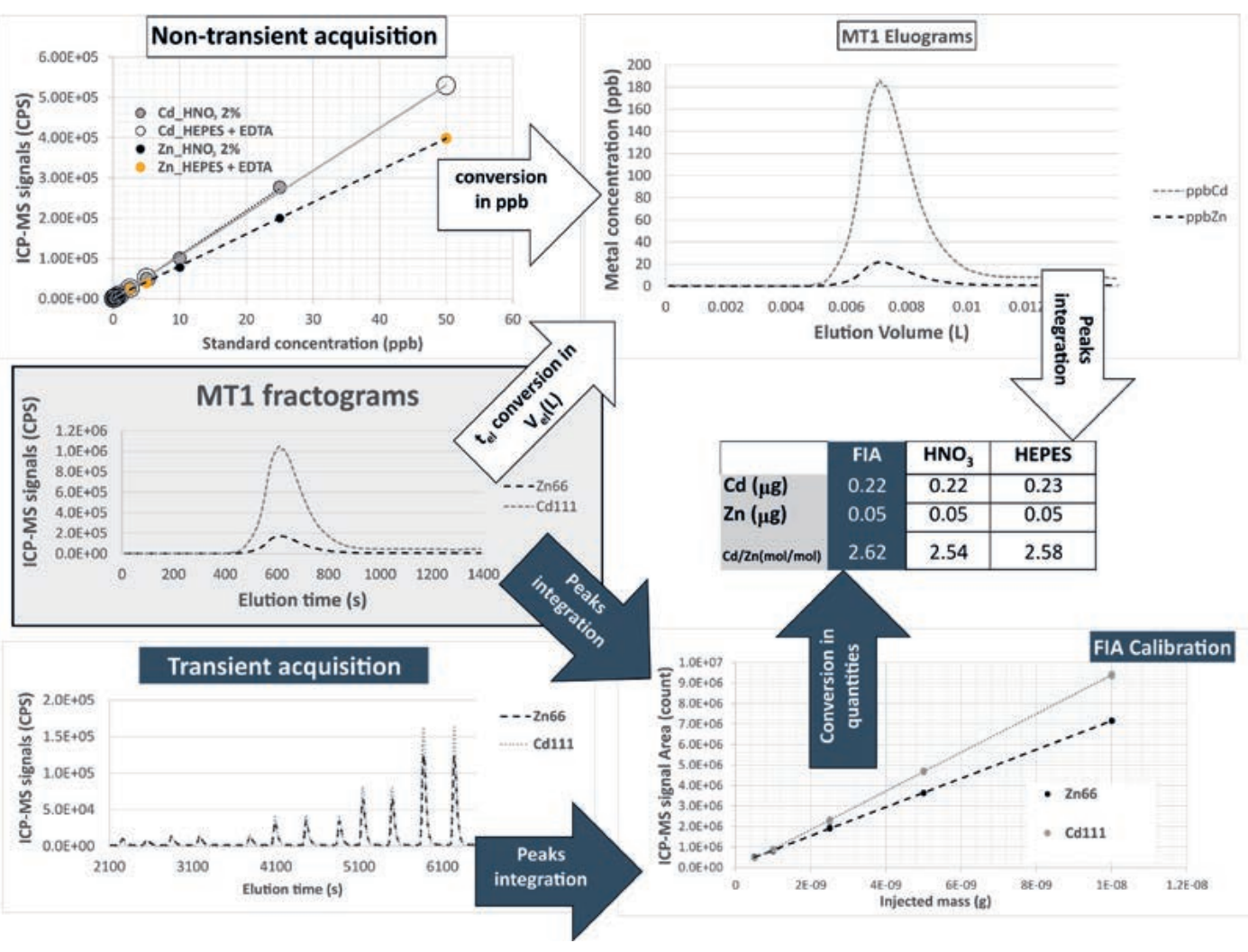

Fig. 2. Quantification of $\mathrm{Cd}$ and $\mathrm{Zn}$ contents in metallothionein (MT1), obtained from the fractograms of ${ }^{111} \mathrm{Cd}$ and ${ }^{66} \mathrm{Zn}$ recorded by direct coupling of AF4 to the nebulizer of the ICPMS, using external calibration made by continuous aspiration of standards prepared either in $2 \% \mathrm{HNO}_{3}$ or in $10 \mathrm{mM} \mathrm{HEPES/}$ $1 \mathrm{mM}$ EDTA (white arrows) or via flow injection analysis (FIA) with standards prepared in 10 mM HEPES/ 1 mM EDTA (dark arrows). The ICP-MS acquisition employed KED with $\mathrm{He}$ as collision gas in an octopole collision cell. MT1 was fractionated using HEPES $10 \mathrm{mM}$ $\mathrm{pH}=7.0$ as eluent. For the nontransient acquisition procedure, the conversion of elution time $\left(t_{e}\right)$ into elution volume $\left(V_{e}\right)$ needs to be performed before integration of the peaks. The quantities (in mass) are converted into moles to assess the atomic ratio of $\mathrm{Cd} / \mathrm{Zn}$, which was around 2.6, independently of the method used and in line with the $\mathrm{Zn}_{2} \mathrm{Cd}_{5}$ stoichiometry of the peptide. The recovery of the protein was estimated to be $80 \%$ of total concentrations of the initial peptide solution diluted in $2 \%$ $\mathrm{HNO}_{3}$ and measured by ICP-MS. (Unpublished results). 
In the case of $\mathrm{Cu}^{2+}$, as for $\mathrm{Zn}^{2+}$ and $\mathrm{Cd}^{2+}$, the change of matrix did not affect the calibrations obtained by non-transient acquisition despite of the high carbon loading when HEPES was used (Fig. S1A in the Supplementary Information). The non-linear behavior of the calibration obtained by non-transient acquisition for $\mathrm{Ag}^{+}$ in the eluent/ligand mixture compared to $2 \% \mathrm{HNO}_{3}$ matrix (Fig. S1B) and the absence of quantitative peaks recorded for FIA (Fig. S1D) suggested that EDTA was not able to prevent its adsorption on the tubing before its introduction into the ICP-MS detector. Other calibration strategies were adopted in the past: $(i)$ use of FIA, with increased quantities of certified and well-stabilized Ag-NPs in HEPES, ${ }^{[43]}$ (ii) use of external calibration of increased concentrations of $\mathrm{AgNO}_{3}$ in a $2 \% \mathrm{HNO}_{3}$ matrix, ${ }^{[44]}$ which were both suitable for AF4-ICP-MS evaluation of Ag size-speciation using HEPES as eluent. No matrix effect was attempted for this metal. Thus, in the case of soft cations (e.g. $\mathrm{Ag}^{+}, \mathrm{Hg}^{2+}$ or $\left.\mathrm{Au}^{3+}\right)$ the use of thiol-ligands, known to have a higher affinity than EDTA, could be used for their stabilization in neutral solutions (i.e. for $\mathrm{Au}^{3+}$ described in section 2.3), provided that they will not result in matrix effects (see section 2.1).

The peristaltic pump of the ICP-MS was used for external calibration, but was disconnected for FIA, leading to increase of the sample flow rate from 0.33 to $0.7 \mathrm{~mL} \mathrm{~min}^{-1}$. It appears as if the sample flow rate only has a minor effect on the analytical results using our ICP-MS set-up. Further experiments need to be performed in order to address main parameters responsible for such an observation (i.e. ICP gas flow rates, type of spray chamber), since variation in sample flow rate is known to affect the sensitivity of ICP-MS detection.

Despite these encouraging results, it has been shown that the size/elemental composition of particles, and in some cases, their crystalline structure, ${ }^{[25]}$ can affect the atomization/ionization of elements in the plasma. Additionally, it was demonstrated that the presence of MNP homo-aggregates could also lead to noisy signals (spikes) if the detector acquisition time is not increased (i.e. from $0.1-0.2 \mathrm{~s}$ to $0.5-1 \mathrm{~s}$ ). ${ }^{[25]}$ Thus, calibration using ionic surrogates, even with matrix-matched strategies should be validated using MNPs, to be extended on the entire size-range/structure of nano-species as found in natural environments.

\subsection{Low Concentration of Analytes: Use of Slot-flow Technology for In-channel Concentration}

The main challenge for high quality quantitative AF4-ICPMS analysis is the low concentration of analytes present in the natural samples. ${ }^{[24,45]}$ Preconcentration procedures may be necessary, but may lead to agglomeration or loss of material especially in the nano-sized range. ${ }^{[6 a, 46]}$ Despite the high capacity for large volumes introduction in the classical AF4 by injection-concentration procedure, the time needed to run a single analysis could be excessive ${ }^{[47]}$ (i.e. $10 \mathrm{~mL}$ injection takes a minimum of $1 \mathrm{~h}$ ). This limitation could be overcome by using slot-flow (split-flow) technology, which offers online analyte enrichment by removing the upper part of the eluent from the channel, and increases the detected signals, as illustrated in Fig. 3

In the specific example shown in Fig. 3, an increase in the slotflow flux leading to a theoretical enrichment factor of 2.8 , only increased the measured nanoparticulate Au by a factor of 1.5 with the ICP-MS, but 2.35 for UVvisD detection. The decrease of the channel outflow (from 0.7 to $0.25 \mathrm{ml} \mathrm{min}^{-1}$ ) led also to an apparent increase in the retention time of Au-NP and had an enlargement effect on the peak distribution for ICP-MS detection. Differences in resolution and experimental enrichment factors among the different on-line detectors have been already pointed out in the past. ${ }^{[47]}$ Only few examples of the use of slot-flow with or without preconcentration of the samples, for the characterization of natural colloids and their associated TMs are available to date, ${ }^{[31,46]}$ but suggested that higher enrichment factors can be obtained. The variability of enrichment factors for ICP-MS detection was shown to be dependent on the composition of MNP, ${ }^{[47]}$ and experimental enrichment factors were often higher than the theoretical one for this study. The signal intensity of ICP-MS we obtained here did not change in accordance with theoretical enrichments, and was lower than expected. Thus, further developments need to be performed in order to increase the benefits of slot-flow uses to increase the amplitude of the ICP-MS signal. The use of microflow nebulizers and certainly other types of spray chamber must be considered for future optimizations. ${ }^{[42]}$

The encouraging results presented herein and the evolution of commercial ICP-MS detectors for the handling of interferences should facilitate the choice of procedure for elemental quantification. However, the above examples also show that available ionic standard surrogates are not always sufficient to obtain quantitative results. The choice of matrix used for cations stabilization in solutions, set-up used for the standards introduction and evaluation on how particulate-size may affect analytes ionization/atomization in complex matrixes need to be investigated. Thus, in the case of MNPs or their hetero-aggregates as found in natural water, further effort should be made to favor the generation of certified reference materials suitable for the optimization of their online concentration and size-determination followed by ICP-MS quantification.

\section{Selected Examples of the Uses of AF4-ICP-MS in Environmental Biogeochemistry and Ecotoxicology}

We illustrate first here the advances made recently in the detection and characterization of MNP behavior in environmental systems by combining the information obtained from AF4-ICP-

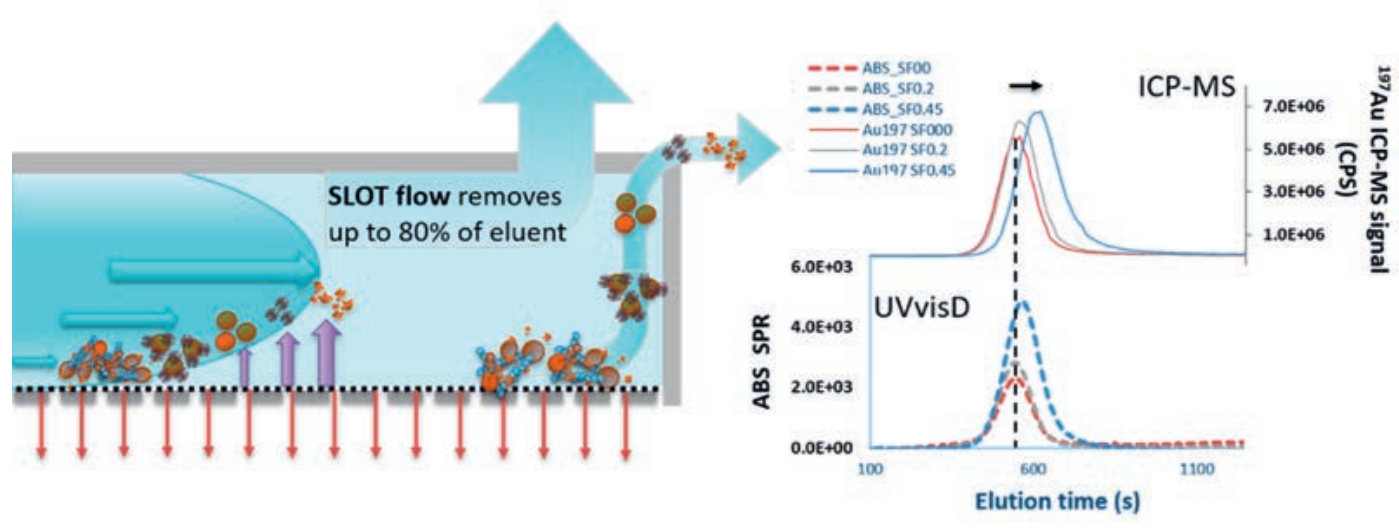

Fig. 3. Effect of increasing slotflow rate $\left(0-0.45 \mathrm{~mL} \mathrm{~min}^{-1}\right)$ on the detection of Au-NP $d_{h}=59$ $\mathrm{nm}$ by UVvisD $(\lambda=520 \mathrm{~nm}$, the surface plasmon resonance (SPR) wavelength) and ICPMS $\left({ }^{197} \mathrm{Au}\right)$. The quantification of the nanoparticulate Au was performed in this case using FIA of $\mathrm{Au}^{3+}$ ionic standard stabilized with $0.1 \mathrm{mM}$ of 2,3-dimercapto1-propanesulfonic acid diluted in HEPES $10 \mathrm{mM} \mathrm{pH} \mathrm{7.0,} \mathrm{biological}$ buffer used as eluent. Detector

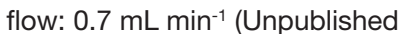
results). 
MS and other 'standard' online AF4 detectors. Then, we illustrate our recent developments in terms of the characterization of ultrasmall colloidal species, and their role on trace metals dispersion, the interactions of TMs with bioproducts and implication on their bioavailability. Finally, we will discuss the interactions of engineered MNP (E-MNPs) with organic matter, leading to the formation of 'eco-' and 'bio'-corona, known to alter their ecotoxicological outputs.

\subsection{Characterization of the Behavior of MNPs}

The use of AF4-ICP-MS accounts for early findings on the environmental behavior of colloidal species and/or their associated trace metals in interconnected watersheds. [48] Natural MNPs (N-MNP) are often characterized as nanoobjects with lower UV-absorbing and/or non-fluorescent, that elute at higher retention times than HS (see section 3.2). For example, in-depth size-based composition and quantities of water-extractable N-MNPs in three forest soils and those contained in stream waters of the same area were characterized by AF4-UVvisD-DLS-ICP-MS, and AF4-OCD (organic carbon detector). ${ }^{[49]}$ The presence of three size-fractions was identified: $(i)$ an organic-rich fraction, associated to a large quantity of $\mathrm{Al}$ and some $\mathrm{Fe}, \mathrm{Mn}$, most probably composed of HS with overlapping small mineral-oxides $\left(d_{h}<20-25 \mathrm{~nm}\right.$, see section 3.2) that is dominant in streams; ( $i i)$ an intermediary fraction $\left(20-25 \mathrm{~nm}<d_{h}<60-70 \mathrm{~nm}\right)$ characterized by the presence of $\mathrm{Ca}$ and $\mathrm{Mn}$ and more visible in streams and soil leachates; and finally, (iii) clay minerals ( $\mathrm{Al} / \mathrm{Si}$ ) with size between $d_{h} 60-70 \mathrm{~nm}$ and $\sim 400 \mathrm{~nm}$, most probably composed by oxides and stabilized by organic matter.[37e] The proportion and size distribution of clay minerals are greater in soil water extracts as they occur in the $d_{h}$ range of 25-240 nm together with 240-500 $\mathrm{nm}$ fractions. ${ }^{[50]}$

Ca-based MNPs, so far largely understudied, have been identified and were shown to occur in significant proportion in the $d_{h}$ range from 20 to $70 \mathrm{~nm}$ fractions in streams located in southern Europe. ${ }^{[51]}$ In addition to HS, Ca-based MNP containing $40 \%$ of OC with $d$ ranging from $30-450 \mathrm{~nm}$ were also identified as transporters of TM, such as U originating from soils. ${ }^{[52]}$ Most of these recent studies revealed that the N-MNP are associated with a large proportion of organic carbon, showing the importance of organic components in their stabilization, and suggesting that more in-depth identification of organic components should be done.

Combining information of size-elemental composition with gyration diameter $\left(d_{g}\right)$ obtained by online MALS measurements allows to characterize the changes in the N-MNP shape along the hydrodynamic size distribution. A change in the shape factor, defined as $\rho=d_{o} / d_{h}$, over the time course of elution is useful to identify their ability to form large aggregates ${ }^{[53]}$ or to identify rod-like shape particles that have higher $\rho$ (2.8) compared to a sphere (0.7). ${ }^{[52,54]}$ The recent introduction of the shape index, defined as $d / d$, that compared the size obtained by MALS for the N-MNP $\left(d_{g}\right)$ and of spherical standards $\left(d_{o s}\right)$ was used to follow the changes of structure of $\mathrm{Fe} / \mathrm{Al} / \mathrm{C}-\mathrm{MNP}$ involved in $\mathrm{U}$ mobilization. ${ }^{[55]}$ This study showed a change in the U-carrier MNPs shape, mainly rod-like and with low $\mathrm{U} / \mathrm{Fe}$ ratio in a pond, into newly formed iron-based spherical particles with higher U/Fe ratio, when the pond was affected by the resurgence of groundwater. The U/Al ratio of rod-like MNPs remained stable suggesting that they were originated from soil drainage.

Additionally, the use of the elemental ratio obtained from ICPMS was applied to decipher between natural oxides nanoparticles and engineered ones e.g. $\mathrm{TiO}_{2}-\mathrm{NPs}$ and $\mathrm{CeO}_{2}-\mathrm{NPs}$, ${ }^{[56]}$ making AF4-ICP-MS a precious tool for assessing the local impact of such emerging contaminants.

\subsection{Interaction of Trace Metals with HS and Small $N-M N P\left(d_{h}<30 \mathrm{~nm}\right)$}

The size-based component distribution of trace metals for low-size analytes can be quantified with set-ups of maximized resolution. This implies that the recovery of low-size components must be achieved by decreasing the pore-size of the membrane, the AF4 channel thickness can be increased to improve the size resolution of separation and combined with signal deconvolution procedures to decipher potential overlapping components. ${ }^{[37 a-c, 45,57]}$ Our recent works illustrate the capabilities of AF4-ICP-MS to provide more comprehensive information on the size-based speciation of trace metals bound to HS and ultra-small colloids, thus providing insights into their biogeochemical role. ${ }^{[37 b, 57]}$

Fig. 4 illustrates how the fractograms obtained by different detectors can be used jointly to identify thenature of colloidal mercury species ( $\mathrm{Hg}$ bound to $\mathrm{HS}$, nanoparticles or hetero-aggregates) in interstitial water of contaminated soil following deconvolution to quantify the components' size distributions. ${ }^{[37 b]}$ This study has also highlighted that the distribution of $\mathrm{Hg}$-containing species varied within the time of the flooding of the soil, and may have implications on the retention of $\mathrm{Hg}$ in the soil and thus its mobilization into the immediate environment, such as a nearby river. Another example includes the measurement of ultra-small iron oxides nanoparticles $\left(d_{h}<15 \mathrm{~nm}\right)$ formation under artificial oxygenation of anoxic pristine wetland pore water. ${ }^{[57]}$ This had consequences on the preferential binding of uranium measured at trace level on the different components. Before and after oxygenation, the U(IV) was found associated to HS. The changes observed for U sizespeciation were due to the binding of $\mathrm{U}(\mathrm{VI})$ to the neo-formed iron$\mathrm{NP}$ and on HS after oxygenation of the sample. Considering the low concentration of $\mathrm{Hg}$ or $\mathrm{U}$ and the number of particles identified, AF4-UVvisD-FluoD-ICP-MS is offering unique possibilities for identification of such small nanoparticles $\left(\right.$ e.g. $\left.d_{h} 7-15 \mathrm{~nm}\right)$ and TM interactions with HS $\left(d_{h}<3 \mathrm{~nm}\right)$ as measured in these two types of samples. In the case of hydrous iron-oxide formation (HFO) upon oxygenation of ferrous iron mixed with organic matter including $\mathrm{HS}$, the hydrodynamic size of HFO with $d_{h}<30 \mathrm{~nm}$ has been determined by AF4-UVvisD-ICP-MS, in contrast to batch dynamic light scattering (DLS) and to sp-ICP-MS/MS which was unable to measure the core-sizes of these ultra-small particles. ${ }^{[58]}$ Indeed, AF4-ICP-MS is the technique of choice when changes in redox and/or HS content occur in interconnected watersheds and may affect trace metal size-speciation. ${ }^{[28,59]}$ AF4-UVvisD-ICP-MS can be also used to follow the changes of agglomeration states of HS, even at small hydrodynamic size of $d_{h}=0.9-3 \mathrm{~nm}$, due to photoalteration, ${ }^{[60]}$ cation promoted aggregation ${ }^{[60]}$ or changes in metal binding capacity of HS upon dilution from river to lake. ${ }^{[37 a]}$

\subsection{TMs and Engineered MNPs Behavior in the Pre- sence of Bio-macromolecules}

Interactions of TMs and E-MNPs with macromolecules either outside or inside cells have important outcomes on their bioavailability and toxic effects. ${ }^{[2 a, 61]}$ The use of AF4-UVvisDMALS-ICP-MS for the size characterization of EPS produced by micro-organisms or purified extracts of bio-macromolecules, as well as their metal-binding properties over size continuum was thus developed. ${ }^{[62]}$ The preferential binding of TMs for low molecular mass (LMM) components, except for $\mathrm{Pb}$ that additionally binds to high molecular mass (HMM) components, was demonstrated. A similar trend was also shown for colloidal components of effluents from waste-water treatment plants. ${ }^{[63]}$ Some of our results have illustrated the importance of size/MM distribution of TMs on the bioavailability of $\mathrm{Fe}, \mathrm{Pb}$, and $\mathrm{Cd}$. ${ }^{[62 b, c, 64]}$ The interactions of bio-produced macromolecules, or more generally the secretome of microorganisms with E-MNP, have rarely been investigated, ${ }^{[65]}$ and even less with AF4-ICP-MS. [24] The stability of Ag-NPs in lake water enriched with exudates 


\section{A_AF4-MD-ICP-MS_colloid characterization}

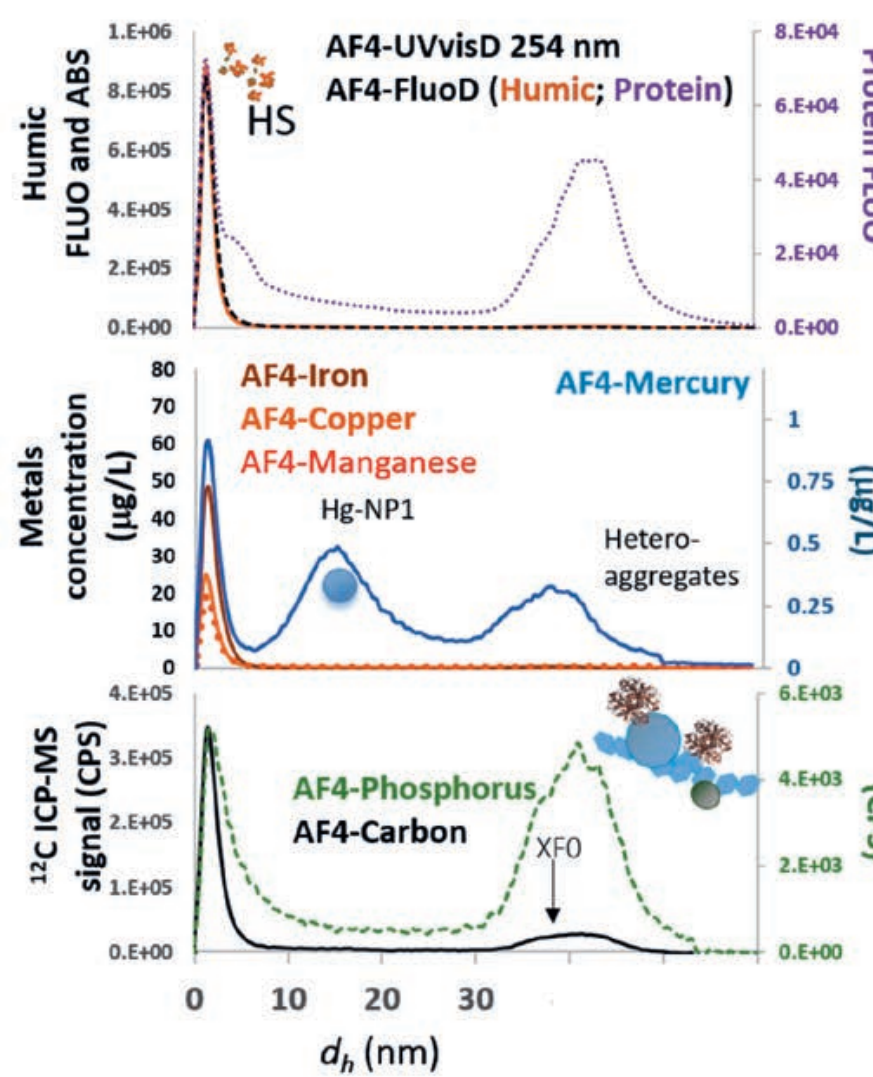

\section{B_QT-AF4-ICP-MS_Size-based speciation}
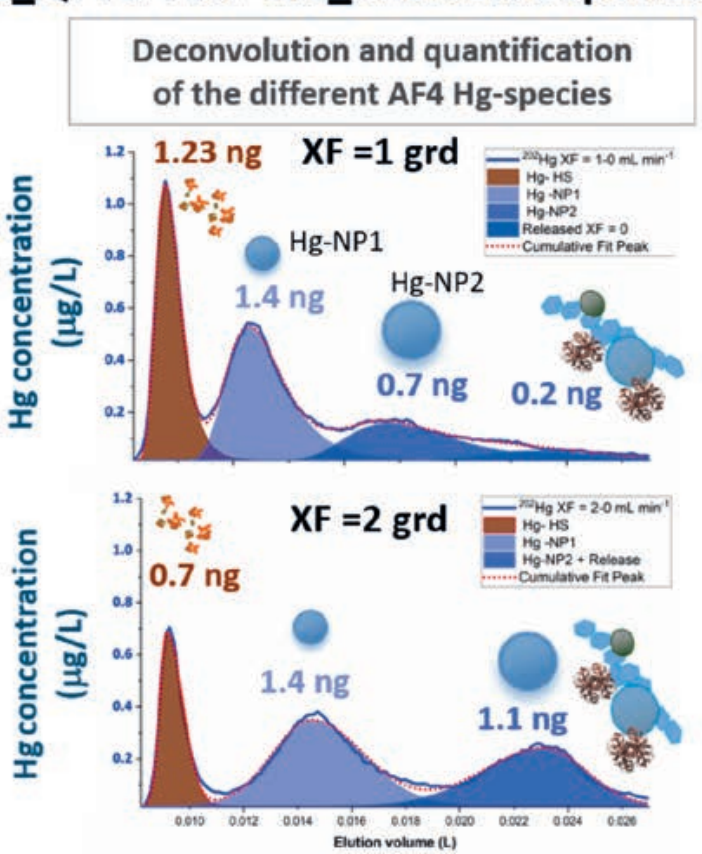

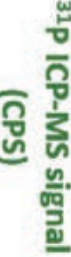

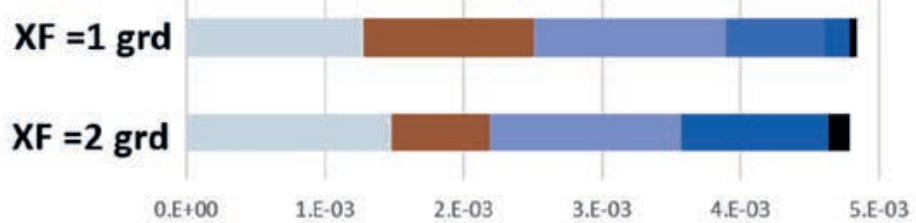

Fig. 4. Use of AF4-FLuoD-UVvisD-ICP-MS to identify AF4 metal species (>1 kDa) in pore water of mercury-contaminated soil using multi-detection linking property-based to elemental composition over size (A) and its use to quantify Hg-species using deconvolution of the Hg signal with two different elution procedures (B). The ICP-MS acquisition was done using $\mathrm{He}$ as collision gas and KED mode to minimize spectral overlap. The signals are presented after base-line corrections. The integration of information provided by the different online detectors allows the determination of the nature and composition of metallic species with $\mathrm{MM}>1 \mathrm{kDa}$. The coelution of $\mathrm{Hg}$ with the material corresponding to the first peak was attributed to its complexation to HS (Hg-HS). HS are characterized by their absorbance at $254 \mathrm{~nm}$ (UVvisD, black line) and specific fluorescence $(\lambda e x=260$ $\mathrm{nm} / \lambda \mathrm{em}=470 \mathrm{~nm}$, FluoD, dashed black lines). Their relatively small size $\left(d_{h}=1.5 \mathrm{~nm}\right)$ obtained by external calibration, together with the strong ${ }^{12} \mathrm{C}$ signal characterizing these components confirmed their organic nature, although a ${ }^{31} \mathrm{P}$ signal of low-intensity appears to be coeluted with protein-like components. Other $\mathrm{Hg}$ species larger than HS were found in such samples with $d_{h} \sim 15 \mathrm{~nm}$ or $d_{h}>30 \mathrm{~nm}$. Most of the other metals (e.g. Fe, Mn, $\mathrm{Cu}$ ) co-eluted together with HS, are well-known to bind to them in aquatic environments. However, none of the other metals analyzed appear to be coprecipitated or included in the larger $\mathrm{Hg}$ species, thus they are likely made of $\mathrm{HgS}$ in nanoparticulate form (Hg-NP), and their larger hetero-aggregates are formed with organic material. The latter were released when the cross-flow was turned-off at the end of elution. By decreasing the cross-flow flux

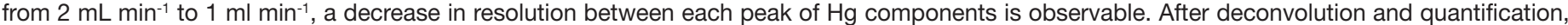
it can be observed that most of the Hg-NPs were found to be $d_{h}<60 \mathrm{~nm}$, with two types of nanoparticle Hg-NP2 $40 \mathrm{~nm}$ and Hg-NP1 $\sim 15 \mathrm{~nm}$ accounting for $15 \%$ and $30 \%$, respectively, whereas hetero-aggregates of $d_{h} \sim 85 \mathrm{~nm}$ only accounted for $4 \%$ of total Hg in the sample. Overall, AF4mercury measurable species accounted for $\sim 70 \%$ of $\mathrm{Hg}$ in this particular sample (adapted from ref. [37b]).

produced from a cyanobacterium Synechocystis sp was thoroughly analyzed ${ }^{[66]}$ using a strategy enabling surface modification of AgNPs to be followed by using AF4-UVvisD on one hand, while Ag-NPs dissolution was screened by batch sp-ICP-MS on the other hand. The results highlight that the presence of EPS leads to the stabilization of Ag-NPs with different surface coatings in surface water; however, this finding strongly depends on the original coating and size of the NPs. Nevertheless, AF4-UVvisDFLuoD-MALS-ICP-MS revealed that citrate-coated Ag-NPs form homo-aggregates that dissolve with time in the presence of preconcentrated HMM components secreted by Synechocystis sp, on which they adsorb to form large hetero-aggregates of size rather difficult to determine even with an online MALS (Fig. 5). This example illustrates the complexity and difficulties encountered in the evaluation of the size of hetero-aggregates and the need to use the information of several online detectors for size measurement to avoid possible misinterpretation of the obtained results only based on analytes retention.

Changes in coating or the nature of components are known to affect the size determination $v s$ hydrodynamic elution of analytes in the channel, by modifying membrane interactions leading to changes in retention. Such a phenomenon has been well-documented for mixtures of Ag-NPs with $d=20 \mathrm{~nm}$ and individual metalloproteins such as, MT1, superoxide dismutase, ceruloplasmin or catalase $\left(\mathrm{MM}=6-250 \mathrm{kDa} ; d_{h}=3-13 \mathrm{~nm}\right)^{[43,44]}$ promoting/impairing the elution of Ag-NPs or individual thiolligands $(\mathrm{MM}=0.121-0.307 \mathrm{kDa})^{[27]}$ decreasing the retention of original Ag-NP. In both cases, however, shifts in Ag-NPs retention time agreed with the protein size or $\mathrm{MM}$ of thiol-ligands suggesting the formation of a bio-corona or coating exchange. 

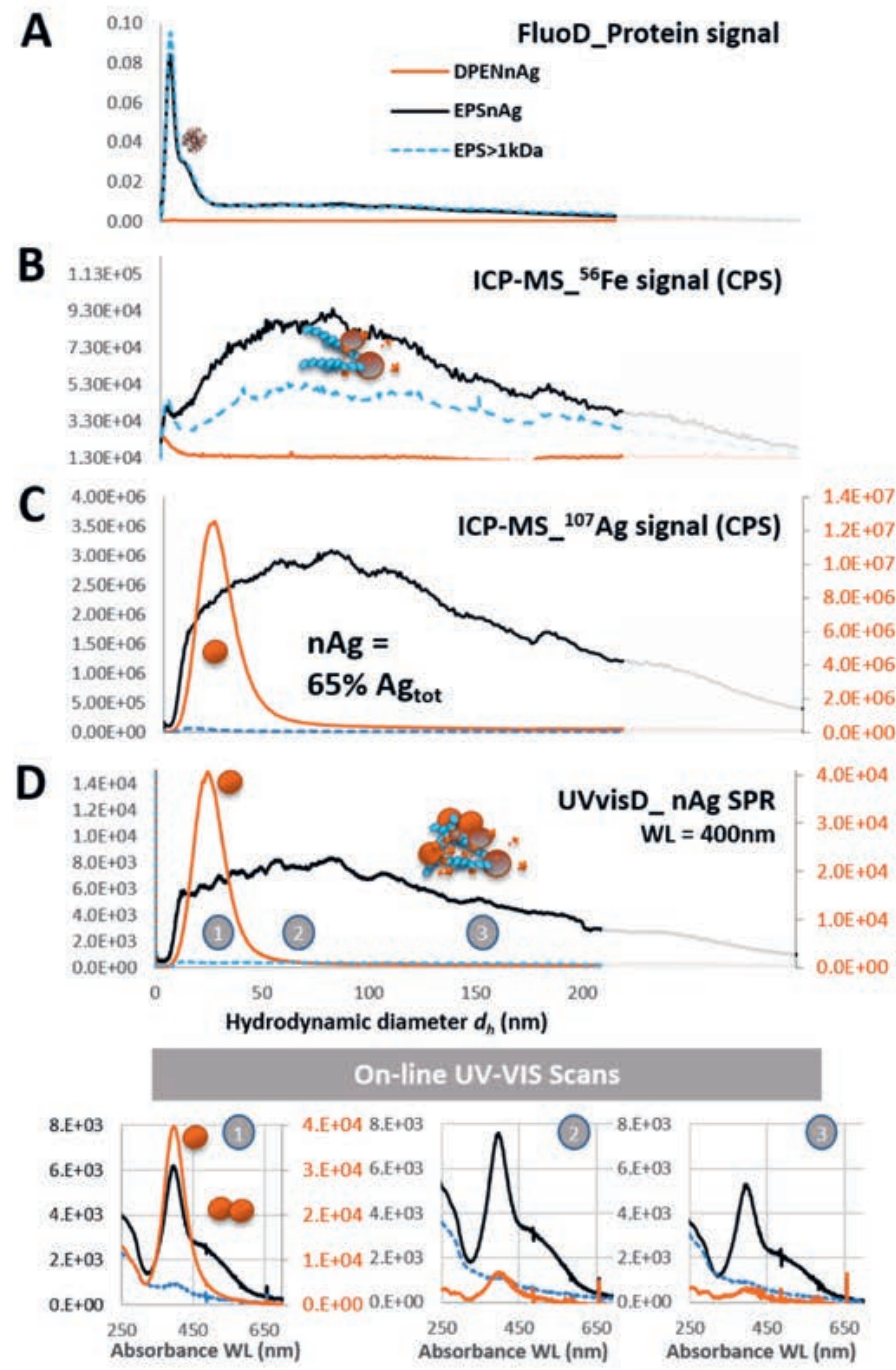

E

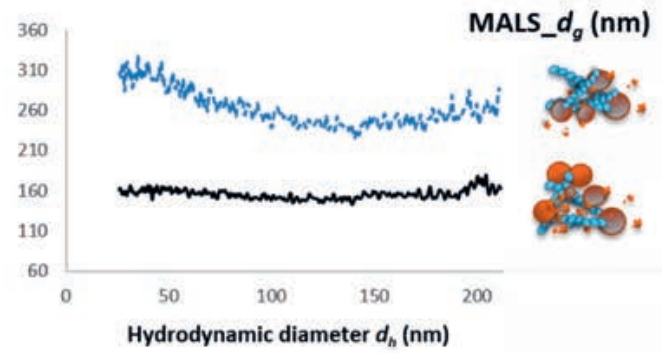

Despite this, aggregation depending on protein/ligand properties, quantification of proteins, metallic exchanges occurring at the metallic cofactor sites, and the dissolution of Ag-NPs can be quantitatively assessed via the use of AF4-UVvisD-FluoD-ICPMS, leading to important information on mechanisms affecting either the catalytic properties of enzymes ${ }^{[43,44]}$ or the biocidal properties and toxicological effects of Ag-NPs coated by thiolligands. ${ }^{[67]}$

AF4-ICP-MS is also applied in the field of environmental nano-metallomics to follow the changes in colloidal stability of Ag-NP externally (culture medium) and their fate inside the cells after their extraction. ${ }^{[69]}$ In addition, by using biomedical samples taken from patients, AF4-ICP-MS measurements were shown to give insights on the leaching of metallic nanoparticles from prostheses for hip replacement and leached metal adsorption on plasmatic proteins at trace level[70] or in plasma metalloprotein changes in terms of metal loading, quantities, and aggregation when patients are suffering from cancer. ${ }^{[20 b]}$
Fig. 5 Characterization of large components of the secretome obtained from cyanobacterium (EPS $>1 \mathrm{kDa}$, blue lines) and their interaction with $20 \mathrm{~nm}$ AgNPs (EPSnAg, black lines) by AF4-MD-ICP-MS. Size distribution is given in hydrodynamic diameter $\left(d_{h}\right)$ obtained by external calibration and compared to AgNPs enrobed with D-penicillamine (DPENnAg, orange lines). The white areas represent the end of separation, with release of unfractionated material. Pre-concentration of EPS was performed by using several centrifugal filtrations on a 1 kDa cut-off membrane of culture medium, from which cyanobacteria were removed by centrifugation and filtration $(<450 \mathrm{~nm})$, after reaching their exponential phase of growth. The HMM fraction contained EPS/ iron-oxides composites, as depicted by elemental ${ }^{56} \mathrm{Fe}$ size-distribution obtained from ICP-MS (B). The LMM consisted of proteins, as revealed by protein-specific fluorescence signal (FluoD, A). ICP-MS fractogram for the elemental detection of ${ }^{107} \mathrm{Ag}(\mathrm{C})$ and UVvisD fractograms to follow Ag-NPs based on their SPR properties (UVvisD_nAgSPR, D), show the monodisperse distribution of DPENnAg with a peak centered at $d_{h}=23 \mathrm{~nm}$ and a SPR band at $\lambda=400 \mathrm{~nm}$, recorded UV-VIS scans 0 . Interaction of Ag-NPs with EPS leads to the appearance of a second SPR band at $\lambda=515 \mathrm{~nm} \mathbf{2} 3$, indicating that some homo-aggregation of Ag-NPs has occurred. The enlarged hydrodynamic size distribution of Ag-NPs (15 $\mathrm{nm}<d_{h}<200 \mathrm{~nm}$ ) recorded by these two detectors suggests the adsorption of slightly homo-aggregated Ag-NPs onto HMM EPS. Quantitative analysis of the Ag signals also indicated that dissolution of Ag-NPs occurred. Sizes measured by MALS (E) show a deviation from the hydrodynamic elution, without any relationship of the $d_{g}$ with estimated $d_{h}$. As well, when Ag-NP adsorbed on HMM, interferences leading to back-scattering of light due to polarizing properties of Ag-NPs ${ }^{[68]}$ led to a decrease from $d_{g}=260 \mathrm{~nm}$ to $d_{g}=$ $140 \mathrm{~nm}$ for estimated size of these composites. These results illustrate the need of online detectors for size measurement and the difficulties encountered for the evaluation of size of hetero-aggregates under our separations conditions. (Unpublished results).

\section{Conclusions and Perspectives}

In this review, we critically discussed the current state-ofthe-art concerning AF4-ICP-MS coupling with an emphasis on the existing challenges and possible solutions when this versatile technique is used for quantification and size-characterization of metal-containing species in complex samples from environmental and biological origin. The combination of the separation power of AF4, covering a wide range of sizes, with different online detectors, shows the great potential of using AF4-ICP-MS for characterizing metal(-loid) species and their behavior at low concentrations, as found in environmental systems. The hyphenation of AF4 and ICP-MS benefits from the relatively high separation power with no stationary phase (AF4) and low limits of detection with elemental selectivity (ICP-MS ${ }^{[71]}$ making this type of analysis attractive in different areas of research from bio-geochemistry of inorganic species to nano-metallomics. ${ }^{[7 b, 72]} \mathrm{AF} 4-\mathrm{ICP}-\mathrm{MS}$ is able to probe important mechanisms such as ligand or metal exchanges, the formation/dissolution of MNPs, corona vs. hetero-aggregates 
formation, and large-scale assessment of dispersion of N-MNP and TMs from soil to interconnected watersheds.

AF4-MD-ICP-MS has grown in popularity because of the need to measure the size distributions of inorganic products (e.g. antibacterial, additives, etc.) to be able to classify them as nanomaterials, considered as emerging contaminants. This technique has been proposed to become a state-of-the-art complementary method for E-MNPs detection, identification, quantification, and further characterization at the early stage of investigation in the field. ${ }^{[73]}$

The recent improvements in quantitative analysis using AF4ICP-MS, however, arose from the need to better characterize the diversity of N-MNP composition and were stimulated by the increased interest in size-based speciation of phosphorus. [37e,38b,49-51,74] The use of ICP-MS for absolute quantification of $\mathrm{C}$ and $\mathrm{P}$ online with $\mathrm{AF} 4{ }^{[37 \mathrm{~d}, \mathrm{e}]}$ has also opened new opportunities for the simultaneous characterization of elemental compositions of inorganic and organic components from macromolecular to large aggregates, the latter playing an important role in the biogeochemical cycling of trace contaminants. Recent studies documented the need for modifying hetero-aggregates isolation processes and for optimizing their introduction into ICP-MS detectors to achieve better quantification. ${ }^{[75]}$ Another alternative could be to develop other modes of elution inside the AF4 channel to improve their resolution, since these large components often exhibit non-Brownian behavior. This was illustrated for the simultaneous quantification of uranium bound to bacteria and their released EPS. ${ }^{[76]}$ The changes in shape factors $(\rho)$ obtained by MALS could be of help to verify the existence of mixed or inverted elution mode (steric vs Brownian) of MNP elution in the channel[77] as well as to optimize separation conditions of hetero-aggregates.

Additionally, the stabilization of N-MNPs and/or their extraction from hetero-aggregates before being fractionated by AF4 will help for their better identification. ${ }^{[78]}$ The latter could also apply to E-MNP isolation and quantification from environmental matrixes. ${ }^{566,79]}$ The combination of AF4-ICP-MS and sp-ICP-MS also provides a promising approach to better characterize the environmental behavior of MNPs, especially when composite analytes with the same hydrodynamic behavior occur simultaneously. ${ }^{[80]}$ The use of ICP-ToF-MS in sp-ICP-MS mode seems to be even more appropriate given its ability for deciphering the elemental composition of MNPs on a singleparticle basis, ${ }^{[81]}$ and its recent use as an online detector for AF4 for characterization of composites E-MNPs. ${ }^{[82]}$

Organic components were also shown to have played an utmost role in natural hetero-aggregates stability in natural waters. Improvements must involve a more in-depth identification of those found to be associated with MNPs in natural water. The off-line uses of other mass spectrometers will be an asset to perform this task. The feasibility of coupling AF4 directly to ESI-MS/MS was proven for lipidomic applications ${ }^{[83]}$ and this type of development may also improve our knowledge in new areas of research such as organic-nano-vector potencies or micro-nano-plastics behavior characterization in environmental and biological samples.

AF4 has acquired a robust place in its application in the pharmaceutical sciences; this has led rapidly to the generation of normalized procedures for the analysis of nano-objects (ISO/TS 21362:2018). Its coupling with ICP-MS should also be further rationalized, allowing homogenization of the results acquired by different users on complex environmental samples obtained from different areas.

\section{Supplementary Information}

Supplementary information is available for this article on https://www.chimia.ch/

\section{Acknowledgements}

Dr. Gabrielle Dublet-Aldi, Dr. Lorenz Gfeller, Pr. Adrien Mestrot (UNIBE) and Pr. Rizlan Bernier-Latmani (EPFL) are acknowledged for our fruitful exchanges and their motivation for improving AF4ICP-MS quantification of colloids in natural samples. Much thanks are also addressed to Ms. Cindy Correia de Almeida for her technical support in sample preparation related to the experiments illustrating the differences in calibration types, the slot-flow effects, and AgNPs interactions with EPS from cyanobacteria, original results of which are presented herein. Thanks are also addressed to Mr. Thibaut Cossart to have taken care of cyanobacteria growth, and Mr. Kevin Trindade, Mr. Killian Kavanagh and Ms. Arin Kantarciyan for active discussions during the conception of the illustrations. We thank Dr. Bodo Hattendorf (ETHZ) for his constructive input during the review process.

\section{Conflict of Interest}

The authors declare that the research was conducted in the absence of any commercial or financial relationships that could be construed as a potential conflict of interest.

\section{Author Contributions}

IAMW and VIS took part in conceptualization, paper writing and editing. IAMW performed AF4-MD-ICP-MS and data analysis for original datasets presented herein and referred as unpublished in the text. VIS acquired the funding. All authors have read and agreed to the published version of the manuscript.

\section{Funding}

The financial support of the Swiss National Science Foundation (Grant number R'Equip 206021_183292) is acknowledged.

Received: October 30, 2022

[1] a) K. J. Wilkinson, J. R. Lead, 'Environmental Colloids and Particles. Behaviour, Separation and Characterisation', Vol. 10, John Wiley Sons, Ltd. Chichester, UK, 2007; b) G. Lespes, T. Zuliani, D. Schaumloffel, Environ. Sci. Pollut. Res. 2016, 23, 15767, https://doi.org/10.1007/s11356-016-6922-8

[2] a) M. Tercier Waeber, S. Stoll, V. I. Slaveykova, Arch. Sci. 2012, 65, 119; b) C. W. Cuss, C. N. Glover, M. B. Javed, A. Nagel, W. Shotyk, Environ. Rev. 2019, 1, https://doi.org/10.1139/er-2019-0014.

[3] Agilent, 'Handbook of Hyphenated ICP-MS Applications', Agilent technologies, 2012.

[4] L. H. Liu, Y. G. Yin, L. G. Hu, B. He, J. B. Shi, G. B. Jiang, Trac - Trends Anal. Chem. 2020, 129, https://doi.org/10.1016/j.trac.2020.115953.

[5] a) L. D. Guo, R. W. Macdonald, Glob. Biogeochem. Cycl. 2006, 20, https://doi.org/10.1029/2005GB002593; b) E. Bolea, M. P. Gorriz, M. Bouby, F. Laborda, J. R. Castillo, H. Geckeis, J. Chromatogr. A 2006, 1129, 236, https://doi.org/10.1016/j.chroma.2006.06.097; c) S. Assemi, G. Newcombe, C. Hepplewhite, R. Beckett, Water Res. 2004, 38, 1467; d) O. S. Pokrovsky, L. S. Shirokova, S. A. Zabelina, T. Y. Vorobieva, O. Y. Moreva, S. I. Klimov, A. V. Chupakov, N. V. Shorina, N. M. Kokryatskaya, S. Audry, J. Viers, C. Zoutien, R. Freydier, Aq. Geochem. 2012, 18, 115, https://doi.org/10.1007/s10498-011-9154-z; e) J. Tsz-Shan Lum, K. Sze-Yin Leung, J. Anal. Atom. Spectrom. 2017, 32, 2127, https://doi.org/10.1039/C7JA00188F.

[6] a) E. Maria, P. Crancon, P. Le Coustumer, M. Bridoux, G. Lespes, Talanta 2020, 208, https://doi.org/10.1016/j.talanta.2019.120383; b) E. Maria, S. Faucher, P. Crancon, G. Lespes, J. Chromatogr. A 2021, 1640, https://doi.org/10.1016/j.chroma.2021.461957; c) Y. X. Lu, X. L. Gao, J. M. Song, C. T. A. Chen, J. L. Chu, Sci. Tot. Environ. 2020, 717, https://doi.org/10.1016/j.scitotenv.2019.135265.

[7] a) S. Faucher, P. Le Coustumer, G. Lespes, Environ. Sci. Pollut. Res. 2018, https://doi.org/10.1007/s11356-018-1646-6; b) A. Malysheva, E. Lombi, N. H. Voelcker, Nat. Nanotechnol. 2015, 10, 835, https://doi.org/10.1038/nnano.2015.224; c) M. D. Montano, F. von der Kammer, C. W. Cuss, J. F. Ranville, J. Anal. Atom. Spectrom. 2019, 34, 1768, https://doi.org/10.1039/c9ja00168a.

[8] M. M. Pornwilard, A. Siripinyanond, J. Anal. Atom. Spectrom. 2014, 29, 1739, https://doi.org/10.1039/c4ja00207e.

[9] M. Mansor, S. Drabesch, T. Bayer, A. Van Le, A. Chauhan, J. Schmidtmann, S. Peiffer, A. Kappler, Environ. Sci. Tech. Lett. 2021, 8, 589, https://doi.org/10.1021/acs.estlett.1c00314.

[10] S. Lee, X. Bi, R. B. Reed, J. F. Ranville, P. Herckes, P. Westerhoff, Environ. Sci. Technol. 2014, 48, 10291, https://doi.org/10.1021/es502422v.

[11] a) J. Kocic, D. Gunther, B. Hattendorf, J. Anal. Atom. Spectrom. 2021, 36, 233, https://doi.org/10.1039/d0ja00421a; b) I. Jreije, 
A. Azimzada, M. Hadioui, K. J. Wilkinson, Molecules 2020, 25, https://doi.org/10.3390/molecules25235516; c) M. Hadioui, G. Knapp, A. Azimzada, I. Jreije, L. Frechette-Viens, K. J. Wilkinson, Anal. Chem. 2019, 91, 13275, https://doi.org/10.1021/acs.analchem.9b04007; d) A. Azimzada, J. M. Farner, M. Hadioui, C. Liu-Kang, I. Jreije, N. Tufenkji, K. J. Wilkinson, Environ. Sci.-Nano. 2020, 7, 139, https://doi.org/10.1039/c9en00951e.

[12] a) M. F. Hochella, Geochim. Cosmochim. Acta 2002, 66, 735 https://doi.org/https://doi.org/10.1016/S0016-7037(01)00868-7; b) M. F. Hochella, D. W. Mogk, J. Ranville, I. C. Allen, G. W. Luther, L. C. Marr, B. P. McGrail, M. Murayama, N. P. Qafoku, K. M. Rosso, N. Sahai, P. A. Schroeder, P. Vikesland, P. Westerhoff, Y. Yang, Science 2019, 363, 1414, https://doi.org/10.1126/science.aau8299.

[13] a) B. F. da Silva, S. Perez, P. Gardinalli, R. K. Singhal, A. A. Mozeto, D. Barcelo, Trac-Trends Anal. Chem. 2011, 30, 528, https://doi.org/10.1016/j.trac.2011.01.008; b) B. Kowalczyk, I. Lagzi, B. A. Grzybowski, Curr. Opin. Coll. Interf. Sci. 2011, 16, 135, https://doi.org/10.1016/j.cocis.2011.01.004; c) H. Weinberg, A. Galyean, M. Leopold, Trac-Trends Anal. Chem. 2011, 30, 72, https://doi.org/10.1016/j.trac.2010.09.006.

[14] I. Kozyatnyk, S. Bouchet, E. Bjorn, P. Haglund, J. Hazard. Mater. 2016 318, 194, https://doi.org/10.1016/j.jhazmat.2016.07.024.

[15] K. Hoffmann, S. Bouchet, I. Christl, R. Kaegi, R. Kretzschmar, Environ. Sci.-Nano. 2020, 7, 1163, https://doi.org/10.1039/c9en01448a.

[16] a) G. Yohannes, M. Jussila, K. Hartonen, M. L. Riekkola, J. Chromatogr. A 2011, 1218, 4104, https://doi.org/10.1016/j.chroma.2010.12.110; b) S. Cao, J. Pollastrini, Y. J. Jiang, Curr. Pharmaceut. Biotechnol. 2009, 10, 382, https://doi.org/10.2174/138920109788488978; c) H. C. Mahler, W. Friess, U. Grauschopf, S. Kiese, J. Pharmaceut. Sci. 2009, 98, 2909, https://doi.org/10.1002/jps.21566; d) R. N. Qureshi, W. T. Kok, Anal. Bioanal. Chem. 2011, 399, 1401, https://doi.org/10.1007/s00216-010-4278-3; e) D. C. Rambaldi, P. Reschiglian, A. Zattoni, Anal. Bioanal. Chem. 2011, 399, 1439, https://doi.org/10.1007/s00216-010-4312-5; f) S. Schachermeyer, J. Ashby, W. W. Zhong, J. Chromatogr. A 2013, 1295, 107, https://doi.org/10.1016/j.chroma.2013.04.063.

[17] M. Baalousha, B. Stolpe, J. R. Lead, J. Chromatogr. A 2011, 1218, 4078, https://doi.org/10.1016/j.chroma.2011.04.063.

[18] a) J. Gigault, J. M. Pettibone, C. Schmitt, V. A. Hackley, Anal. Chim. Acta 2014, 809, 9, https://doi.org/10.1016/j.aca.2013.11.021; b) B. Meisterjahn, E. Neubauer, F. Von der Kammer, D. Hennecke, T. Hofmann, J. Chromatogr. A 2014, 1372, 204, https://doi.org/10.1016/j.chroma.2014.10.093.

[19] G. Lespes, V. D. Du Pont, J. Sep. Sci. 2021, https://doi.org/10.1002/jssc.202100595.

[20] a) A. Siripinyanond, S. Worapanyanond, J. Shiowatana, Environ. Sci. Technol. 2005, 39, 3295, https://doi.org/10.1021/es0483802; b) J. Y. Kim, H. B. Lim, M. H. Moon, Anal. Chem. 2016, 88 , 10198, https://doi.org/10.1021/acs.analchem.6b02775; c) A. Al-Ammar, A. Siripinyanond, R. M. Barnes, Spectrochim. Acta B 2001, 56, 1951, https://doi.org/10.1016/s0584-8547(01)00337-8.

[21] B. Lyven, M. Hassellov, C. Haraldsson, D. R. Turner, Anal. Chim. Acta 1997, 357, 187, https://doi.org/10.1016/s0003-2670(97)00565-5.

[22] B. Stolpe, M. Hassellov, K. Andersson, D. R. Turner, Anal. Chim. Acta 2005, 535, 109, https://doi.org/10.1016/j.aca.2004.11.067.

[23] R. Mildner, S. Hak, J. Parot, A. Hyldbakk, S. E. Borgos, D. Some, C. Johann, F. Caputo, Eur. J. Pharmaceut. Biopharmaceut. 2021, 163, 252, https://doi.org/10.1016/j.ejpb.2021.03.004.

[24] Q. S. Bai, Y. G. Yin, Y. W. J. Liu, H. W. Jiang, M. X. Wu, W. D. Wang, Z. Q. Tan, J. F. Liu, M. H. Moon, B. S. Xing, Appl. Spectrosc. Rev. 2021, https://doi.org/10.1080/05704928.2021.1935272.

[25] S. Motellier, A. Guiot, S. Legros, B. Fiorentino, J. Anal. Atom. Spectrom. 2014, 29, 2294, https://doi.org/10.1039/C4JA00213J.

[26] M. Loula, A. Kana, O. Mestek, Talanta 2019, 202, 565, https://doi.org/10.1016/j.talanta.2019.04.073.

[27] I. A. M. Worms, W. Liu, A. Arnould, F. Rollin-Genetet, C. Vidaud, R. Soulas, J.-F. Damlencourt, S. Motellier, E. Mintz, I. Michaud-Soret, D. TruffierBoutry, Interactions Of AgNPs with bioligands: direct quantification of dissolution and aggregation using AF4-UVD-MALLS-ICP-MS, https://www.cea.fr/cea-tech/pns/nanosafe/en/Pages/SPECIAL-PAGES/ Local-search.aspx?k=Worms\&kq=Worms\#.

[28] E. Neubauer, S. J. Köhler, F. von der Kammer, H. Laudon, T. Hofmann, Environ. Sci. Technol. 2013, 47, 7120, https://doi.org/10.1021/es401193j.

[29] T. K. Mudalige, H. Qu, S. W. Linder, Anal. Chem. 2015, 87, 7395, https://doi.org/10.1021/acs.analchem.5b01592.

[30] A. Sánchez-Cachero, S. López-Sanz, N. R. Fariñas, Á. Ríos, R. d. C. R. Martín-Doimeadios, Talanta 2021, 222, 121513 , https://doi.org/https://doi.org/10.1016/j.talanta.2020.121513.

[31] X. Diaz, W. P. Johnson, D. Fernandez, D. L. Naftz, Appl. Geochem. 2009, 24, 1653, https://doi.org/10.1016/j.apgeochem.2009.04.031

[32] T. May, R. H. Wiedmeyer, Atom. Spectrosc. 1998, 19, 150.
[33] a) T. S. Lum, K. S. Y. Leung, J. Anal. Atom. Spectrom. 2016, 31, 1078 https://doi.org/10.1039/c5ja00497g; b) V. Balaram, Rapid Commun. Mass Spectrom. 2021, 35, https://doi.org/10.1002/rcm.9065.

[34] N. Sugiyama, Y. Shikamori, J. Anal. Atom. Spectrom. 2015, 30, 2481 , https://doi.org/10.1039/c5ja00308c.

[35] S. Theiner, A. Schoeberl, L. Fischer, S. Neumayer, S. Hann, G. Koellensperger Analyst 2019, 144, 4653, https://doi.org/10.1039/c9an00039a.

[36] a) Q. Zhang, J. T. Snow, P. Holdship, D. Price, P. Watson, R. E. M. Rickaby, J. Anal. Atom. Spectrom. 2018, 33, 1196, https://doi.org/10.1039/ c8ja00031j; b) N. Yamada, Spectrochim. Acta B 2015, 110, 31, https://doi.org/10.1016/j.sab.2015.05.008.

[37] a) I. A. M. Worms, H. E. Chmiel, J. Traber, N. Tofield-Pasche, V. I. Slaveykova, Environ. Sci. Technol. 2019, 53, 14134, https://doi.org/10.1021/acs.est.9b02184; b) L. Gfeller, A. Weber, I Worms, V. I. Slaveykova, A. Mestrot, Biogeosci. 2021, 18, 3445, https://doi.org/10.5194/bg-18-3445-2021; c) C. W. Cuss, I. Grant-Weaver, W. Shotyk, Anal. Chem. 2017, 89, 8027, https://doi.org/10.1021/acs.analchem.7b01427; d) V. Nischwitz, N. Gottselig, A. Missong, T. Meyn, E. Klumpp, J. Anal. Atom. Spectrom. 2016, 31, 1858, https://doi.org/10.1039/C6JA00027D; e) N. Gottselig, V. Nischwitz, T. Meyn, W. Amelung, R. Bol, C. Halle, H. Vereecken, J. Siemens, E. Klumpp, Vadose Zone J. 2017, 16, 12, https://doi.org/10.2136/vzj2016.07.0064.

[38] a) I. C. Regelink, G. F. Koopmans, C. van der Salm, L. P. Weng, W. H. van Riemsdijk, J. Environ. Qual. 2013, 42, 464 https://doi.org/10.2134/jeq2012.0322; b) S. Baken, I. C. Regelink, R. N. J. Comans, E. Smolders, G. F. Koopmans, Water Res. 2016, 99, 83, https://doi.org/10.1016/j.watres.2016.04.060; c) B. Stolpe, L. D. Guo, A. M. Shiller, G. R. Aiken, Geochim. Cosmochim. Acta 2013, 105, 221, https://doi.org/10.1016/j.gca.2012.11.018.

[39] E. Bolea-Fernandez, D. Leite, A. Rua-Ibarz, T. Liu, G. Woods, M. Aramendia, M. Resano, F. Vanhaecke, Anal. Chim. Acta 2019, 1077, 95, https://doi.org/10.1016/j.aca.2019.05.077.

[40] a) T. Narukawa, T. Iwai, K. Chiba, J. Anal. Atom. Spectrom. 2017, 32, 1547 , https://doi.org/10.1039/C7JA00132K; b) I. F. Seregina, M. A. Bolshov, K. Ossipov, Spectrochim. Acta B: Atom. Spectrosc. 2021, 177, 106034, https://doi.org/10.1016/j.sab.2020.106034.

[41] F. Laborda, J. Medrano, J. R. Castillo, Anal. Chim. Acta 2000, 407, 301, https://doi.org/10.1016/S0003-2670(99)00806-5.

[42] D. Profrock,A. Prange, Appl. Spectrosc. 2012, 66, 843, https://doi.org/10.1366/12-06681.

[43] W. Liu, I. A. M. Worms, N. Herlin-Boime, D. Truffier-Boutry, I. MichaudSoret, E. Mintz, C. Vidaud, F. Rollin-Genetet, Nanoscale 2017, 9, 6581, https://doi.org/10.1039/c7nr01075c

[44] W. Liu, I. A. M. Worms, V. I. Slaveykova, Environ. Sci.: Nano. 2020, https://doi.org/10.1039/C9EN01284B.

[45] Y. Wang, C. W. Cuss, W. Shotyk, J. Chromatogr. A 2020, 1632, https://doi.org/10.1016/j.chroma.2020.461600.

[46] T. Saito, Y. Suzuki, T. Mizuno, Coll. Surf. A: Physicochem. Engin. Asp. 2013, 435, 48, https://doi.org/10.1016/j.colsurfa.2012.11.031.

[47] H. Prestel, R. Niessner, U. Panne, Anal. Chem. 2006, 78, 6664 https://doi.org/10.1021/ac0602591.

[48] a) S. Dubascoux, I. Le Hécho, M. Hassellöv, F. Von Der Kammer, M. Potin Gautier, G. Lespes, 'Field-flow fractionation and inductively coupled plasma mass spectrometer coupling: History, development and applications', Vol. 25, 2010; b) M. Baalousha, J. Lead, Y. Ju-Nam, P. Wilderer, Treat. Water Sci. 2011, 3, 89 .

[49] A. Missong, S. Holzmann, R. Bol, V. Nischwitz, H. Puhlmann, K. von Wilpert, J. Siemens, E. Klumpp, Sci. Tot. Environ. 2018, 634, 305, https://doi.org/10.1016/j.scitotenv.2018.03.265.

[50] A. Missong, R. Bol, V. Nischwitz, J. Kruger, F. Lang, J. Siemens, E. Klumpp, Plant Soil 2018, 427, 71, https://doi.org/10.1007/s11104-017-3430-7.

[51] N. Gottselig, W. Amelung, J. W. Kirchner, R. Bol, W. Eugster, S. J. Granger, C. Hernandez-Crespo, F. Herrmann, J. J. Keizer, M. Korkiakoski, H. Laudon, I. Lehner, S. Lofgren, A. Lohila, C. J. A. Macleod, M. Molder, C. Muller, P. Nasta, V. Nischwitz, E. Paul-Limoges, M. C. Pierret, K Pilegaard, N. Romano, M. T. Sebastia, M. Stahli, M. Voltz, H. Vereecken, J. Siemens, E. Klumpp, Glob. Biogeochem. Cycl. 2017, 31, 1592, https://doi.org/10.1002/2017gb005657.

[52] C. Claveranne-Lamolere, G. Lespes, S. Dubascoux, J. Aupiais, F. Pointurier, M. Potin-Gautier, J. Chromatogr. A 2009, 1216, 9113 https://doi.org/10.1016/j.chroma.2009.08.025.

[53] M. Baalousha, F. V. D. Kammer, M. Motelica-Heino, H. S. Hilal, P. Le Coustumer, J. Chromatogr. A 2006, 1104, 272, https://doi.org/10.1016/j.chroma.2005.11.095.

[54] H. El Hadri, G. Lespes, P. Chery, M. Potin-Gautier, Anal. Bioanal. Chem 2014, 406, 1111, https://doi.org/10.1007/s00216-013-7104-X.

[55] S. Harguindeguy, P. Crancon, M. P. Gautier, F. Pointurier, G. Lespes, Environ. Sci. Pollut. Res. 2019, 26, 5294, https://doi.org/10.1007/s11356-018-2732-5.

[56] a) J. J. Wang, M. M. Nabi, S. K. Mohanty, A. Afrooz, E. Cantando, N. Aich, M. Baalousha, Chemosphere 2020, 248, 
https://doi.org/10.1016/j.chemosphere.2020.126070; b) Z. B. Yi, F. Loosli, J. J. Wang, D. Berti, M. Baalousha, Environ. Chem. Lett. 2020, 18, 215, https://doi.org/10.1007/s10311-019-00926-5.

[57] G. Dublet, I. Worms, M. Frutschi, A. Brown, G. C. Zund, B. Bartova, V. I. Slayeykoya, R. Bernier-Latmani, Environ. Sci. Technol. 2019, 53, 9361, https://doi.org/10.1021/acs.est.9b01417.

[58] C. Moens, N. Waegeneers, A. Fritzsche, P. Nobels, E. Smolders, J. Chromatogr. A 2019, 1599, 203, https://doi.org/10.1016/j.chroma.2019.04.032.

[59] C. W. Cuss, M. W. Donner, I. Grant-Weaver, T. Noernberg, R. Pelletier, R. N. Sinnatamby, W. Shotyk, Sci. Tot. Environ. 2018, 642, 1242, https://doi.org/10.1016/j.scitotenv.2018.06.099.

[60] I.A. M. Worms, D. Adenmatten, P. Mieville, J. Traber, V. I. Slaveykova, Chemosphere 2015, 138, 908, https://doi.org/10.1016/j.chemosphere.2014.10.093.

[61] V. I. Slaveykova, M. T. Li, I. A. Worms, W. Liu, CHIMIA 2020, 74, 115 , https://doi.org/10.2533/chimia.2020.115.

[62] a) E. Alasonati, S. Dubascoux, G. Lespes, V. I. Slaveykova, Environ. Chem. 2010, 7, 215, https://doi.org/10.1071/en09148; b) C. S. Hassler, E. Alasonati, C. A. M. Nichols, V. I. Slaveykova, Marine Chem. 2011, 123, 88, https://doi.org/10.1016/j.marchem.2010.10.003; c) L. Norman, I. A. M. Worms, E. Angles, A. R. Bowie, C. M. Nichols, A. N. Pham, V. I. Slaveykova, A. T. Townsend, T. D. Waite, C. S. Hassler, Marine Chem. 2015, 173, 148, https://doi.org/10.1016/j.marchem.2015.03.015.

[63] I. A. M. Worms, Z. A. G. Szigeti, S. Dubascoux, G. Lespes, J. Traber, L. Sigg, V. I. Slaveykova, Water Res. 2010, 44, 340, https://doi.org/10.1016/j.watres.2009.09.037.

[64] a) V. I. Slaveykova, N. Parthasarathy, K. Dedieu, D. Toescher, Environ. Pollut. 2010, 158, 2561, https://doi.org/10.1016/j. envpol.2010.05.016; b) I. A. M. Worms, J. Traber, D. Kistler, L. Sigg, V. I. $\begin{array}{lllll}\text { Slaveykova, } \quad \text { Environ. } & \text { Pollut. } & \text { 2010, } & \text { 158, }\end{array}$ https://doi.org/10.1016/j.envpol.2009.09.007.

[65] N. Sani-Kast, J. Labille, P. Ollivier, D. Slomberg, K. Hungerbühler, M. Scheringer, Proc. Natl. Acad. Sci. USA 2017, 114, E1756, https://doi.org/10.1073/pnas.1608106114.

[66] J. Jimenez-Lamana, V. I. Slaveykova, Sci. Tot. Environ. 2016, 573, 946, https://doi.org/10.1016/j.scitotenv.2016.08.181.

[67] M. Marchioni, G. Veronesi, I. Worms, W. L. Ling, T. Gallon, D. Leonard, C. Gateau, M. Chevallet, P. H. Jouneau, L. Carlini, C. Battocchio, P. Delangle, I. Michaud-Soret, A. Deniaud, Nanoscale Horizons 2020, 5, 507, https://doi.org/10.1039/c9nh00286c.

[68] a) K. Loeschner, J. Navratilova, S. Legros, S. Wagner, R. Grombe, J. Snell, F. von der Kammer, E. H. Larsen, J. Chromatogr. A 2013, 1272, 116, https://doi.org/10.1016/j.chroma.2012.11.053; b) B. Schmidt, K. Loeschner, N. Hadrup, A. Mortensen, J. J. Sloth, C. B. Koch, E. H. Larsen, Anal. Chem. 2011, 83, 2461, https://doi.org/10.1021/ac102545e.

[69] E. Bolea, J. Jimenez-Lamana, F. Laborda, I. Abad-Alvaro, C. Blade, L. Arola, J. R. Castillo, Analyst 2014, 139, 914, https://doi.org/10.1039/c3an01443f.

[70] K. Loeschner, C. F. Harrington, J.-L. Kearney, D. J. Langton, E. H. Larsen, Anal. Bioanal. Chem. 2015, 407, 4541, https://doi.org/10.1007/s00216-015-8631-4.

[71] B. Meermann, Anal. Bioanal. Chem. 2015, 407, 2665, https://doi.org/10.1007/s00216-014-8416-1.

[72] C. Contado, Anal. Bioanal. Chem. 2017, 409, 2501, https://doi.org/10.1007/s00216-017-0180-6.
[73] a) Y. Ju-Nam, J. R. Lead, Sci. Tot. Environ. 2008, 400, 396, https://doi.org/10.1016/j.scitotenv.2008.06.042; b) R. D. Handy, F. von der Kammer, J. R. Lead, M. Hassellov, R. Owen, M. Crane, Ecotoxicol. 2008 17, 287, https://doi.org/10.1007/s10646-008-0199-8.

[74] a) N. Gottselig, J. Sohrt, D. Uhlig, V. Nischwitz, M. Weiler, W. Amelung, Sci. Tot. Environ. 2020, 717, 12, https://doi.org/10.1016/j.scitotenv.2019.134638; b) G. Moradi, R. Bol, L. Trbojevic, A. Missong, R. Morchen, B. Fuentes, S. M. May, E. Lehndorff, E. Klumpp, Glob. Planet. Change 2020, 185, 8 , https://doi.org/10.1016/j.gloplacha.2019.103090; c) A. Missong, S. Holzmann, R. Bol, V. Nischwitz, H. Puhlmann, K. v. Wilpert, J. Siemens, E. Klumpp, Sci. Tot. Environ. 2018, 634, 305, https://doi.org/10.1016/j.scitotenv.2018.03.265

[75] J. J. Yang, P. Tan, T. Y. Huang, V. Nischwitz, Anal. Chim. Acta 2020, 1093, 16, https://doi.org/10.1016/j.aca.2019.09.044

[76] B. P. Jackson, J. F. Ranville, A. L. Neal, Anal. Chem. 2005, 77, 1393, https://doi.org/10.1021/ac049278q.

[77] a) M. Baalousha, F. V. D. Kammer, M. Motelica-Heino, P. Le Coustumer, J. Chromatogr. A 2005, 1093, 156, https://doi.org/10.1016/j.chroma.2005.07.103; b) S. Dubascoux, F. Von Der Kammer, I. Le Hecho, M. P. Gautier, G. Lespes, J. Chromatogr. A 2008, 1206, 160, https://doi.org/10.1016/j.chroma.2008.07.032.

[78] a) A. I. Ivaneev, S. Faucher, M. S. Ermolin, V. K. Karandashev, P. S. Fedotov, G. Lespes, Anal. Bioanal. Chem. 2019, 411, 8011, https://doi.org/10.1007/s00216-019-02147-9; b) F. Loosli, Z. B. Yi, J. J. Wang, M. Baalousha, Sci. Tot. Environ. 2019, 682, 663, https://doi.org/10.1016/j.scitotenv.2019.05.206; c) F. Loosli, Z. B. Yi, J. J. Wang, M. Baalousha, Sci. Tot. Environ. 2019, 677, 34, https://doi.org/10.1016/j.scitotenv.2019.04.301.

[79] F. Loosli, J. J. Wang, M. Sikder, K. Afshinnia, M. Baalousha, Sci. Tot. Environ. 2020, 715, https://doi.org/10.1016/j.scitotenv.2020.136927.

[80] A. Barber, S. Kly, M. G. Moffitt, L. Rand, J. F. Ranville, Environ. Sci.-Nano. 2020, 7, 514, https://doi.org/10.1039/c9en00637k.

[81] a) K. Mehrabi, R. Kaegi, D. Gunther, A. Gundlach-Graham, Environ. Sci. Nano. 2021, 8, 1211, https://doi.org/10.1039/d0en01066a; b) A. Praetorius, A. Gundlach-Graham, E. Goldberg, W. Fabienke, J. Navratilova, A. Gondikas, R. Kaegi, D. Gunther, T. Hofmann, F. von der Kammer, Environ. Sci.-Nano. 2017, 4, 307, https://doi.org/10.1039/c6en00455e.

[82] O. Meili-Borovinskaya, F. Meier, R. Drexel, M. Baalousha, L. Flamigni, A. Hegetschweiler, T. Kraus, J. Chromatogr. A 2021, 1641, 461981 , https://doi.org/https://doi.org/10.1016/j.chroma.2021.461981.

[83] J. Y. Kim, G. B. Lee, J. C. Lee, M. H. Moon, Anal. Chem. 2021, 93, 4867, https://doi.org/10.1021/acs.analchem.0c04756.

\section{License and Terms}

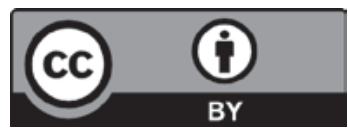

This is an Open Access article under the terms of the Creative Commons Attribution License CC BY 4.0. The material may not be used for commercial purposes.

The license is subject to the CHIMIA terms and conditions: (https://chimia.ch/chimia/about).

The definitive version of this article is the electronic one that can be found at https://doi.org/10.2533/chimia.2022.34 